\title{
The Negative Impact of Social Media during COVID-19
}

\author{
Astha Kumari \\ Medical Intern, Department of Community Medicine, Jawaharlal Nehru Medical College, Datta Meghe \\ Institute of Medical Sciences (DU), Sawangi (Meghe), Wardha, Maharashtra, Pincode-442001; \\ Review Article \\ Conflict of Interest: None
}

\begin{abstract}
:
It has been observed that social media platforms have had both a positive and negative effect on how India has dealt with the COVID 19 pandemic. As the coronavirus took over the world, many took to social media to learn about how the virus spreads and what it is. Although this helped inform everyone on how to take precautions against this deadly virus, a lot of the information that users were reading was not verified or fact-checked and labeled as "fake news".

In the modern world, information is spread very quickly through a variety of social media platforms. Because of this, there was widespread panic even before the COVID-19 virus had even reached India. Many citizens bought an excessive surplus of supplies such as masks, hand sanitizers, and food, which ultimately led to a shortage of these supplies for the 1.3 billion people in this country. The shortage of supplies along with the lockdown process which severely impacted the economy has led to an increase in price to the majority of essential products such as food, hand sanitizers, masks, etc. The most affected were the average day workers.

Social media has caused widespread panic and hogging of essential supplies along with false facts of the virus itself, however, there are some things that we have benefited from due to social media. For example, social media has shown us the importance of social distancing and activities that we can do to keep our mental health in check while under lockdown.

In short, I believe social media should be regulated and kept under watch by the government in certain aspects when it comes to spreading information about pandemics like covid19. If regulated properly we can avoid mass panic and anarchy and will be able to survive this pandemic as one.
\end{abstract}

KEYWORDS:Social Media;Coronavirus;Pandemic; COVID 19;Fake News;

\section{INTRODUCTION:}

The coronavirus is also known as COVID 19 is a respiratory tract illness that is caused by a form of acute resp syndrome. It is a derivative of the SARS-CoV-2 infection. The widespread of the disease made it a major health challenge for the public, worldwide. The effect of COVID 19 upon the world has been exaggerated due to numerous rumours, hoaxes, and information that has not been factchecked. ${ }^{1}$ The first few cases of COVID 19 were seen in late December 2019, that's when this mysterious disease was reported in Wuhan, China which has now become a pandemic. $^{2}$

These bits of fake news have managed to spread more rapidly through all sources of social media than the reliable sources, causing an imbalance and damage to the authenticity within the news ecosystem. The disease has sparked many debates and has shaken the health care system worldwide. ${ }^{3}$ It has led to a cynical effect on people, through social media within a country of over 350 million social media users and a large population that isn't aware of factful resources. ${ }^{4}$

Over the last decade, people have been using social media platforms for selfawareness and knowledge about health care. In the initial few months of COVID19, it was observed that people from various countries were found dependent on social media to seek information about the virus.

Unfortunately, the same social media platforms that many used to learn about the virus also contained information that 
was not fact-checked. These unchecked bits of information were labeled as "fake news". $4-8$

Recent analysis has proved that in the 2016 presidential election in USA fake news was more spread than authentic sources. ${ }^{8}$ Even before the virus affected India, the widespread panic was instigated across the country through social media, which reduced the availability of sanitizers and masks to a point where a majority of the population was lacking these essential products. The country was in chaos because of rumours like transmission of the virus by air and its survival on different surfaces. ${ }^{9}$ These rumours coupled with the fear and stress of lockdown, isolation, and quarantine affected the mental health of individuals, in form of depression, anxiety, phobia, trauma, etc. ${ }^{10}$

Considering the positive aspects of Social Media that is awareness of people, most people started implementing isolation, social distancing and quarantine to combat COVID 19. ${ }^{11}$ Many started wearing masks such as cloth masks, surgical masks, and N95 masks. However, a greater number of N95 masks being purchased and used by normal people during daily routine work led to its shortage of frontline health care workers. $^{12}$

COVID-19 being the less researched disease has caused a lot of confusion about its treatment and prevention among people. Discovery of ayurvedic immunity booster medicines and even religious ways of prevention of COVID 19 was spread among the people which caused confusion at a wide scale and the rumours created social stigma which resulted in people into reduced compliance with proper safety procedures. ${ }^{9}$

There were many incidents where hundreds and thousands of people got infected due to the negligence of one person, ignoring the social distancing protocols. ${ }^{13}$ People were scared of COVID 19 because of fake news like, COVID-19 patients and suspects are getting killed in China in mass numbers and the possibility of extension of lockdown ${ }^{9}$ which also led to social stigma towards travelers from abroad and their contacts. Even northeast Indians were facing racial discrimination as being considered the cause of the outbreak of the disease. ${ }^{12}$ The fear of infection among people also led to suicide, the first suicide case in India took place on $12^{\text {th }}$ February, ${ }^{14}$ followed by two more cases $^{15}$

The first study on the impact of social media can be traced back to the 2009 $\mathrm{H} 1 \mathrm{~N} 1$ pandemic when the misinformation was found to be $4.5 \%$ and usage of terms like Swine Flu was more often than H1N1 Virus. $^{17}$

WHO declared that they are not just fighting the worldwide pandemic but also a social media infodemic. ${ }^{18}$

ABC News reported a Poll from social media claiming the spread of anxiety from Coronavirus faster than the virus itself. ${ }^{19}$

Brewer on BBC News said a lot of misinformation about COVID-19 has created panic, anxiety among society. ${ }^{20}$

Rothschild and Fischer stated that social media is the cause of fear and panic among its users. ${ }^{21}$

Mollasays in 24hours there were 19 million acknowledgments of COVID 19 on social media and various new websites. $^{22}$

Victor says that Chinese citizens struggle to get adequate facts about COVID 19, making them dependent on social media for it. ${ }^{23}$

Similarly, Emmottas claimed by European Union Document, Russian media published a "significant disinformation campaign" to create chaos and panic among the public of western countries. ${ }^{24}$

Devlinsays there was one another cause of panic noticed, which was pictures of empty shops on social media. ${ }^{25}$

El-Treksays this is an era where everyone is an expert and wants to be heard. Therefore, they send various messages and pictures related to COVID-19. ${ }^{26}$

Garrettsays we have given the power to social media, which caused chaos. ${ }^{27}$ 
La et alsays The Vietnamese case is a perfect example of how to establish an authentic network with the citizen, using social media. The country's ministers made specific accounts where they published all the information about COVID-19 to the people. $^{28}$

The above-mentioned facts signify the utmost need for the Indian government to control the freedom of social media and making sure of an appropriate balance of use and misuse. Keeping in mind that the complete banning of social media will cause disliking of the current governing power, leading to distrust. ${ }^{8}$ Researchers claim a negative impact of the Ebola virus suggested to understand the importance of making people aware educate so to channel the use of social media in a positive direction to build better adherence and compliance to control measures. ${ }^{6,7}$ Legal provisions were completely overlooked by the experts who demanded amendments in 123- years old 'The Epidemic Diseases Act 1897'. ${ }^{16}$

So, I strongly believe there is a need for legal provisions in this Act to enforce regulations on social media with a plan keeping in mind the measures mentioned above during COVID 19 and future epidemics.

\section{Vaccine content on social media:}

Information about the vaccine is available on social media and the internet with various studies showing how the vaccines are depicted on these platforms. ${ }^{29-34}$

Basch et al. did an investigation on 87 YouTube videos using two keywords "vaccine safety" and "vaccines and children",35

$65 \%$ of the videos portrayed the antivaccine sentiment.

$5.6 \%$ were published by government officials

And $6.8 \%$ had no relation to science. ${ }^{35}$

When looked for top searched YouTube videos of COVID-19, 27.5\% of those videos had no scientifically accurate information and has 60 million views. ${ }^{36}$ Studies depict anti-vaccine content have more engagement. Anti-vaccine tweets are found to be 4.13-fold more likely to be re-tweeted than any normal tweets. ${ }^{37}$ Also 150 posts were found on Instagram with \#HPV with a substantially higher average number of likes. ${ }^{30}$ Gunaratne et al. proven antivaccine tweets saw a declamatory surge in 2015 which occurred with the measles outbreak. Also, the release of a film called vaxxed and the publication of a book called vaccine whistleblower. ${ }^{31}$ Antivaccine subject matter on Twitter comes together into a specific community which consists of like-minded people and mostly are around \#cdcwhistleblower and \#vaxxed proponents. ${ }^{38}$ Subject matter related to Anti-vaccination is found to be channelized among people who share the same opinion and portrays a structure of debate among these people, strengthening the prior ideas than reinforcing new ones. ${ }^{39}$ The spread of COVID-19 has led to severe social media discourse, with tweets related to covid-19 every 45millisecond and hashtag \#coronavirus becoming $2^{\text {nd }}$ most popular in $2020 .{ }^{40,41}$ Unfortunately, the number of misleading information about COVID-19 is increasing by every day and is becoming dangerous for treatment purposes. $^{42,43}$

Basch et al. and Nan et al. investigated that approach to vaccine-critical websites have a negative affect to vaccinate ${ }^{44,45} \mathrm{~A}$ short interval of exposure to such websites, like 5 to10 minutes lead to an increase in ideologies of vaccine risk among the population. ${ }^{44}$ Bhattacharyya et al. made a social network stimulation model which shows a significant impact from a small vaccine adverse event. ${ }^{46}$ The model also depicted that the cause of the outbreak of vaccine-preventable disease is spreading misleading information on the adverse effect of vaccines on social media platforms. $^{46}$

Social media users show a greater number of skewed populations who are not 
familiar with the consequences of vaccinepreventable diseases ${ }^{47}$

Social media gist on vaccination tend to be shared more frequently than well explained medically justified information. Few social media users suffering from cognitive impairment, low literacy rate, and old age have been found more emotionally taken towards these social media appeals. ${ }^{48}$

The Cultural, religious Background and Political beliefs of users have also been shown to modify their reaction towards social media appeals. ${ }^{47}$

Helge et al. did a study of 400 participants with different ideologies related to flu vaccines.

This study helped us understand how the information is channeled, perceived, and manipulated.It has been observed that participants frequently alter the information based on their attitude, for example, the information was better received if it aligns with the person's baseline attitude. $^{49}$

A Case-control study depicted that parents of both, vaccinated and non-vaccinated children seek information from an antivaccine organization and considers it reliable. $^{50}$

In a similar study done on a group of students, they were exposed to all the vaccine-related websites and $59 \%$ of them weren't able to identify the fake/ misleading websites and 50\% accounted for statements that were inaccurate in relation to vaccination after thorough exposure. ${ }^{51}$

\section{Leveraging social media platforms:}

Medical professionals are considered to be the most trusted source of information to vaccine-hesitant parents who tend to approach anti-physicians. ${ }^{50,52,53,54}$

Direct communication should be built between medical professionals and the patients to reduce the anxiety and concerns of patients. ${ }^{52,55}$ Health care professionals should communicate directly to the patients using the social media platform. ${ }^{56,57}$ Also Medical Professionals should also build a better profile and improve their reach on social media accelerating the promotion of authentic evidence-based information. ${ }^{57}$ Shoup et al. discovered that the effective intervention of social media is the one where there is balanced information which would acknowledge patients concerns but also avoid scientific jargon. ${ }^{58}$

It is a necessity that social media should identify, flag, and block potential harmful misinformation and promote advertisement of information from health agencies. ${ }^{59}$

Social media platforms should redirect vaccine-related researches to handpicked information from health agencies like WHO and CDC. additionally, should have disabled COVID and vaccine-related advertisements to avoid user-driven misleading information. ${ }^{59}$

\section{DISCUSSION:}

The article was written to emphasize the need for fact-checking the news on social media before being released so that there's no intended chaos. It has been observed that a high volume of information spread through social media can lead to media fatigue compromising the needful behaviors essential for an individual's protection. False information that has been promoted through social media include improper washing techniques, social distancing, and false facts of how the virus spreads. Many people have been infected with COVID-19 due to following these improper techniques, believing that they were true. These unchecked facts have affected both the physical and mental health of numerous people. For example, an Indian father of three was reported to commit suicide upon hearing the diagnosis of COVID-19 because he had come to believe that there was no hope of recovery from this disease. ${ }^{60}$

In Nigeria, Doctors and scientists have found many cases of death due to overdose 
of chloroquine (a drug primarily used to treat a malarial parasite) after hearing about the efficacy of the drug which spawned and circulated through multiple social media outlets. ${ }^{61}$

One of the main effects that social media has had on people was observed in the united states. Due to rumours of national lockdown (before the government decided to address the nation about the upcoming lockdown) which was leaked by unknown sources through social media, it fueled a mass panic of buying groceries and this is turn disturbed the supply chain because of increasing insecurity of availability of food in people, especially among the lowincome individuals. Many healthcare works that dedicated their time and energy to handle the situation were not able to acquire enough food and provisions for themselves since the majority of the stores were out of stock. ${ }^{62}$

A resident of Tirunelveli city of Tamil Nadu, Hari Singh, owner of 110 years old Iruttu Kadai died on June 25. Mr. Hari Singh was admitted to the hospital for his Urinary tract infection when he found that he is COVID-19 positive. His family members informed vice news that he was very scared and stressed watching the news about the disease and that very day he was found dead by the hospital staff. The superintendent informed the Indian Express that Mr. Singh died by suicide. ${ }^{63}$

Researchers tracked all non-COVID-19 deaths and found out of 884 deaths recorded 125 were suicide cases reason of death being fear of infection, quarantine, loneliness, and lack of freedom. ${ }^{63}$

Mr. Himanshu Vaswani, a resident of Mumbai and a businessman was found COVID-19 positive on June $1^{\text {st }}$. He told vice news "conflicting news online" that COVID19 has caused him confusion and made him paranoid. Reading about the disease daily made him crazy. ${ }^{63}$

Dr. Harjit Singh Batii, a doctor in Delhi at Manipal Hospital said he had a 27-yearold patient who was COVID 19 positive. When she was informed about her condition "she started crying and shouting. She asked, "how did I get it? How will I be saved?", Batti said. He also mentioned that the panic in emergency wards are "Human nature" even the counselling has been found of no use to such patients because of the misleading news about the disease they have been reading online. ${ }^{63}$

A farmer in Chittoor district in Andhra Pradesh was reported dead on February $11^{\text {th }}$ by suicide because he assumed, he was suffering from COVID-19 and could not be saved. Another farmer in Uttar Pradesh committed suicide because he wanted to save his village from getting infected by COVID-19. ${ }^{63}$

All these cases got the attention of the government and the government in Kerala and Maharashtra employed mental health counsellors to counsel the patients going through isolation and even quarantine to keep a track of their anxiety and depression. $^{63}$

Social media has made it hard to differentiate fact from fiction. Since COVID 19 is a new disease there is very little we know about it. New research about the disease may carry less legitimacy. It has been observed that a new social stigma around this infection has reduced compliance with home quarantine and social isolation. There have been many reported incidences in which one person that is infected, infects a multitude of people who chose not to take the advice of healthcare workers and visit churches and events. $^{14}$

Journalists have mentioned an alarming rise in fake, misleading news online. Many conspiracy theories, herbal cures, one being Patanjali's COVID-19 cure which was flagged as misleading- are the cause of chaos. ${ }^{63}$

Potential strategies to ensure effective health communication on COVID 19

Living life under quarantine, isolation, and at risk of contracting an infectious disease may alter the mental status of many individuals which may affect their physical health as well. Because of all these 
compiling stress factors, it may evoke interest in learning how to live with the disease and learning about the virus itself. $^{64}$ The world health organization acknowledged that the flow of correct information may help with these everyday stresses. The WHO has decided to partner up with several social media platforms such as Facebook, Twitter, Instagram, Google, YouTube, Microsoft, etc. to eradicate the fraud and unchecked information about coronavirus, and in turn, promote actual critical updates from healthcare agencies. ${ }^{65}$

\section{To promote accurate information} certain steps must be followed:

First and foremost frontline providers should be kept updated by real not reel information so that they can use it for better caregiving and can have better communication with the patients, relatives, and the population at risk. Integration of technology has been proven beneficial in giving proper patient care and in the management of mass casualty. ${ }^{66}$

Secondly, mass media, government, and non-government groups and organizations may lead to the spread of fake news. It is crucial to building a strong partnership at local and global levels in a planned manner so that needful and accurate information is shared between various platforms.

Online platforms should focus more on removing all hoaxes and rumours. The modern-day data mining algorithm is more than capable of detecting the unique characteristics of all kinds of fake news and removing them from said platform. ${ }^{9}$ Twitter, Reddit, Amazon, and few more social media platforms are using it to remove fake accounts. All social media platforms should consider adopting such measures to eliminate potential harmful misinformation and rumours.

People who are the cause behind the spread of such fake news should be tracked and asked to answer for it.
Authorities and law enforcement agencies should be made aware of the changes proposed and be able to deal with them. Many countries have already initiated a change within their government and enforcement. ${ }^{67}$ The first step before enforcing these regulations worldwide is to conduct proper planning and investigation to ensure the legal rights of the convicts.

Along with these regulations, the strategies planned for filtering news on social media should be considered and implemented. The news should be circulated in various languages to reach more people ${ }^{68-70}$.

Measures should be taken to provide medical care and provision of information, easily to people living in a rural area and the elderly population by the Telemedicine approach. This way people will stay at home following social distancing and there will be a decrease in the risk of hospitalacquired infection.

Lastly, everyone should avoid any sort of promotion of misleading, fake information related to COVID-19 for the betterment of the population ${ }^{71-72}$.

\section{ACKNOWLEDGEMENT:}

I would like to thank Dr. Ashwin Shailesh for their time and expert advice in reviewing the article.

\section{FUNDING INFORMATION:}

No funding was initiated

\section{CONFLICT OF INTERESTS:}

The author declared no potential conflicts of interest concerning the research, authorship, and/or publication of this article.

\section{REFERENCES}

1. Raman Sandhya. "Public health experts worry about the spread of COVID-19 misinformation". March 18, 2020. Available from: URL: 
https://www.rollcall.com/2020/03/18/p ublic-health-experts-worry-aboutspread-of-covid-19-misinformation/

2. World Health Organisation. Coronavirus. 2020. Available from URL: https://www.who.int/healthtopics/coronavirus\#tab=tab_2 [accessed 2020-04-07]

3. Amir H. Pakpour, Mark D. Griffiths. "The fear of COVID-19 and its role in preventive behaviors". Journal of Concurrent Disorders. $3^{\text {rd }}$ April 2020. Vol. 2 No. 1, 2020 (58-63). Available from:

URL:https://concurrentdisorders.ca/20 20/04/03/the-fear-of-covid-19-and-itsrole-in-preventive-behaviors/

4. NorinaUsman, Mohammed A Mamun, Irfan Ullah. "COVID-19 infection risk in Pakistani health-care workers: The cost-effective safety measures for developing countries". Soc health behave 2020 (cited 2020Aug 29) 3:75$7 . \quad$ Available from: URL:http://www.shbonweb.com/articl e.asp? issn $=2589$ 9767; year $=2020 ;$ volume $=3$; issue $=3 ;$ sp age $=75$; epage $=77$; aulast $=$ Usman

5. Sandhya Keelery."Fake news in India statistics and facts". July $15^{\text {th }} 2020$. Available from: URL: https://www.statista.com/topics/5846/f ake-news-in-india/(6 April 2020, date last accessed).

6. Depoux A, Martin S, Karafillakis E et al. "The pandemic of social media panic travels faster than the COVID-19 outbreak." Journal of Travel Medicine, Volume 27, Issue 3, April 2020, taaa031, Available from: URL: https://academic.oup.com/jtm/article/2 7/3/taaa031/5775501

7. Heidi J Larson. "The biggest pandemic risk? Viral misinformation. Nature 2018; 562:309." $18^{\text {th }}$ October 2018. Available from: URL: https://www.researchgate.net/publicati on/328326703_The_biggest_pandemic _risk_Viral_misinformation
8. Heidi J Larson. "Blocking information on COVID-19 can fuel the spread of misinformation.

Nature 2020; 580:306." $\quad 30^{\text {th }} \quad$ March 2020. Available from: URL: https://www.nature.com/articles/d4158 6-020-00920-w

9. Shu K, Sliva A, Wang S, Tang J, Liu H. "Fake News Detection on Social Media." SIGKDD Explor. Newsl. 19, 1 (June 2017), 22-36. Available from: URL:

https://dl.acm.org/doi/10.1145/313759 7.3137600

10. Times of India. Fact check: truth behind fake news on times of India. https://timesofindia.indiatimes.c om/times-fact-check (6 April 2020, date last accessed).

11. Samantha K Brooks, Rebecca K Webster, Louise E Smith, Lisa Woodland, Simon Wessely, Neil Greenberg, Gideon James Rubin. "The psychological impact of quarantine and how to reduce it: rapid review of the evidence". 14-20 March 2020. Available from: URL: https://www.sciencedirect.com/science /article/pii/S0140673620304608,

12. Laura Hawryluck, Wayne L. Gold, Susan Robinson, Stephen Pogorski, Sandro Galea, Rima Styra." Aggregated COVID-19 suicide incidences in India: Fear of COVID-19 infection is the prominent causative factor". August 2020. Available from: URL:

https://www.sciencedirect.com/science /article/pii/S016517812031489X\#bib0 004

13. Sakib, N., Bhuiyan, A.K.M.I., Hossain, S. et al. Psychometric Validation of the Bangla Fear of COVID-19 Scale: Confirmatory Factor Analysis and Rasch Analysis. Int J Ment Health Addiction (2020). Available from: URL:

https://link.springer.com/article/10.100 7\%2Fs11469-020-00289-x\#citeas 
14. MashuraShammi, Md. Bodrud-Doza, Abu Reza Md. Towfiqul Islam, Md. Mostafizur Rahman. "COVID-19 pandemic, socioeconomic crisis and human stress in resource-limited settings: A case from Bangladesh" May 2020. Available from: URL: https://www.sciencedirect.com/science /article/pii/S2405844020309075

15. Shammi, M., Bodrud-Doza, M., Islam, A.R.M.T. et al. Strategic assessment of COVID-19 pandemic in Bangladesh: comparative lockdown scenario analysis, public perception, and management for sustainability. Environ Dev Sustain (2020).https://link.springer.co m/article/10.1007/s10668-020-00867y\#citeas

16. WHO. "Rolling Updates on Coronavirus Disease (COVID-19). Available from: URL: https://www.who.int/emergencies/dise ases/novel-coronavirus-2019/eventsas-they-happen

17. Chew C, Eysenbach G. "Pandemics in the age of Twitter: content analysis of Tweets during the 2009 H1N1 outbreak." PLoS One 2010 Nov 29;5(11):e14118. Available on URL: Pandemics in the Age of Twitter: Content Analysis of Tweets during the 2009 H1N1 Outbreak (plos.org)

18. Hao $\mathrm{K}$, Basu T. "The coronavirus is the first true social-media infodemic."February $12,2020$. Available from URL: The coronavirus is the first true social-media "infodemic" | MIT Technology Review

19. Muwahed J. "Coronavirus pandemic goes viral in the age of social media, sparking anxiety." 14 March 2020, 03:31 Available from URL: https://tinyurl.com/ybnms2se or Coronavirus pandemic goes viral in the age of social media, sparking anxiety ABC News

20. Brewer K. "Coronavirus: How to protect your mental health." $16^{\text {th }}$
March 2020. Available from URL: https://www.bbc.com/news/healt h-51873799

21. Rothschild N. "Coronavirus panic sells as alarmist information flies on social media." $6^{\text {th }}$ March 2020. Available from

URL: https://www.axios.com/coronavi rus-social-media-b56326b6-ab164c8a-bc86-e29b06e5ab2b.html

22. Molla R. "How coronavirus took over social media."12 $2^{\text {th }}$ March 2020. Available from URL: https://tinyurl.com/ycwtmx3u

23. Victor D. "Panic and Criticism Spread on Chinese Social Media Over Coronavirus." $24^{\text {th }}$ Jan 2020. Available from URL: https://www.nytimes.com/2020/ 01/24/world/asia/china-social-mediacoronavirus.html

24. Emmott R. "Russia deploying coronavirus disinformation to sow panic in West, EU document says". $18^{\text {th }} \quad$ March 2020.

URL: https://tinyurl.com/yx42jzyh

25. Devlin H. Don't let coronavirus tip society into panic, say psychologists. $6^{\text {th }}$ March 2020. Available from URL: https://www.theguardian.com/ science/2020/mar/06/dont-letcoronavirus-tip-society-into-panic-saypsychologists

26. El-Terk N. "Toilet paper, canned food: What explains coronavirus panic buying." $13^{\text {th }}$ March 2020. Available from

URL: https://tinyurl.com/ww23bb3

27. Garrett O. "A Case of Modern Mass Hysteria? The Coronavirus." $13^{\text {th }}$ February 2020. Available from URL: https://tinyurl.com/yarx6j7r

28. La V, Pham T, Ho M, Nguyen M, P. Nguyen K, Vuong T, et al. "Policy Response, Social Media and Science Journalism for the Sustainability of the Public Health System Amid the COVID-19 Outbreak: The Vietnam Lessons. Sustainability 2020 Apr 07;12(7):2931. Available from 
URL:Sustainability | Free Full-Text | Policy Response, Social Media and Science Journalism for the Sustainability of the Public Health System Amid the COVID-19 Outbreak: The Vietnam Lessons (mdpi.com) or [CrossRef]

29. EkramS, DebiecKE, PumperMA, More noMA. "Content and commentary: HPV vaccine and YouTube." $1^{\text {st }}$ April2019;32(2):153-57. Available from URL:Content and Commentary: HPV Vaccine and YouTube - Journal of Pediatric and Adolescent Gynecology (jpagonline.org).

30. BaschCH, MacLeanSA. "A content analysis of HPV related posts on Instagram." Hum Vaccin Immunother. $30^{\text {th }}$ January 2019;15(78):1476-78. Available from URL: Full article: A content analysis of HPV related posts on instagram (tandfonline.com)

31. GunaratneK, CoomesEA, HaghbayanH . "Temporal trends in anti-vaccine discourse on twitter." Vaccine. $9^{\text {th }}$ July 2019;37(35):4867-71. Available from URL: Temporal trends in anti-vaccine discourse on Twitter - ScienceDirect

32. DaviesP, ChapmanS, LeaskJ. "Antivac cination activists on the world wide web." Arch Dis Child. 2002;87(1):2225. Available from URL: Antivaccination activists on the world wide web | Archives of Disease in Childhood (bmj.com)

33. ArifN, AlJefriM, BizziIH, PeranoGB, GoldmanM, HaqI, ChuaKL, Mengozzi M, NeunezM, SmithH. "Fake news or weak science? Visibility and characterization of antivaccine webpages returned by google in different languages and countries."Front

Immunol. 2018;9:1215. Available from URL: Frontiers | Fake News or Weak Science? Visibility and Characterization of Antivaccine Webpages Returned by Google in
Different Languages and Countries Immunology (frontiersin.org)

34. OdoneA, FerrariA, SpagnoliF, Visciare 1liS, SheferA, PasquarellaC, Signorelli C. "Effectiveness of interventions that apply new media to improve vaccine uptake and vaccine coverage." Hum Vaccin Immunother. $1^{\text {st }}$ November 2014, 2015;11(1):72. Available from URL:Full article: Effectiveness of interventions that apply new media to improve vaccine uptake and vaccine coverage (tandfonline.com).

35. BaschCH, ZybertP, ReevesR, BaschC E. "What do popular YouTube TM videos say about vaccines?" Child Care Health Dev. 2017;43(4):499. Available from URL: What do popular YouTube TM videos say about vaccines? - PubMed (nih.gov)

36. LiHO, BaileyA, HuynhD, ChanJ. "You Tube as a source of information on COVID-19: A pandemic of misinformation?" BMJ Global Health. 2020;5(5):e002604. Available from URL: YouTube as a source of information on COVID-19: a pandemic of misinformation? | BMJ Global Health

37. BlankenshipEB, GoffME, YinJ, TseZT $\mathrm{H}, \mathrm{FuK}-$

W, LiangH, SarohaN, FungICH. "Senti ment, contents, and retweets: a study of two vaccine-related twitter datasets." Perm J. 2018;22:17-138. Available from URL: YouTube as a source of information on COVID-19: a pandemic of misinformation? | BMJ Global Health

38. Ortiz-OspinaE. "The rise of social media." $18^{\text {th }} \quad$ September 2019. Available from URL: https://ourworldindata.org/rise-ofsocial-media.

39. YuanX, SchuchardRJ, CrooksAT. "Ex amining emergent communities and social bots within the polarized online vaccination debate in twitter." Social Media + Society. July 2019;5(3):205630511986546. 
Available from URL: Web of Science [v.5.32] - Web of Science Core Collection Full Record (webofknowledge.com)

40. JosephsonA, LambeE. "Brand communications in time of crisis." $2^{\text {nd }}$ April 2020. Available from URL: https://blog.twitter.com/en_us/topics/c ompany/2020/Brand-communicationsin-time-of-crisis.html.

41. CinelliM, QuattrociocchiW, GaleazziA , Valensise CM, Brugnoli E, Schmidt AL, Zola P, Zollo F, Scala S. "The COVID-19 social media infodemic." 2020. Available from URL:

https://arxiv.org/abs/2003.05004.

42. BrennenS, SimonF, HowardP, Nielsen R. "Types, sources, and claims of COVID-19

misinformation." 2020. Available from URL:

https://search.proquest.com/docview/2 387269560.

43. KouzyR, Abi JaoudeJ, KraitemA, El Alam MB, Karam B, Adib E, Zarka J, Traboulsi C, Akl EW, Baddour K. "Coronavirus goes viral: quantifying the COVID-19 misinformation epidemic on twitter." Cureus. 13 ${ }^{\text {th }}$ March 2020;12(3):e7255. Available from URL: [2003.05004] The COVID-19 Social Media Infodemic (arxiv.org)

44. BetschC, RenkewitzF, BetschT, Ulshöf erC. "The influence of vaccine-critical websites on perceiving vaccination risks." J Health Psychol. 15 ${ }^{\text {th }}$ April 2010;15(3):446-55. The influence of vaccine-critical websites on perceiving vaccination risks - PubMed (nih.gov)

45. NanX, MaddenK. "HPV vaccine information in the blogosphere: how positive and negative blogs influence vaccine-related risk perceptions, attitudes, and behavioral intentions." Health Commun. 27 ${ }^{\text {th }}$ March 2012;27(8):829-36. Available from URL:HPV Vaccine Information in the Blogosphere: How Positive and
Negative Blogs Influence VaccineRelated Risk Perceptions, Attitudes, and Behavioral Intentions: Health Communication: Vol 27, No 8 (tandfonline.com)

46. BhattacharyyaS, VuthaA, BauchCT. “ The impact of rare but severe vaccine adverse events on behaviour-disease dynamics: A network model." Sci Rep. $9^{\text {th }} \quad$ May $2019 ; 9(1): 7164-13$. Available from URL: The impact of rare but severe vaccine adverse events on behaviour-disease dynamics: a network model - PubMed (nih.gov)

47. BullerDB, WalkoszBJ, BertelettiJ, Pag otoSL, BibeauJ, BakerK, HillhouseJ, H enryKL. "Insights on HPV vaccination in the united states from mothers' comments on facebook posts in a randomized trial." Hum Vaccin Immunother. $11^{\text {th }}$ June $2019 ; 15(7-$ 8):1479-87. Available from URL: Full article: Insights on HPV vaccination in the United States from mothers' comments on Facebook posts in a randomized trial (tandfonline.com)

48. CallenderD. "Vaccine hesitancy: more than a movement." $11^{\text {th }}$ April 2016;12(9):2464-68. Available from URL: Full article: Vaccine hesitancy: More than a movement (tandfonline.com)

49. GieseH, NethH, MoussaïdM, BetschC, GaissmaierW. "The echo in fluvaccination echo chambers: selective attention trumps social influence." Vaccine. 2019. Available from URL: The echo in flu-vaccination echo chambers: Selective attention trumps social influence - PubMed (nih.gov)

50. SalmonDA, MoultonLH, OmerSB, de HartMP, StokleyS, HalseyNA. "Factor $\mathrm{s}$ associated with refusal of childhood vaccines among parents of school-aged children: A case-control study." Arch Pediatr Adolesc Med. $5^{\text {th }}$ May 2005;159(5):470-76. Available from URL: Factors associated with refusal of childhood vaccines among parents 
of school-aged children: a case-control study - PubMed (nih.gov)

51. KortumP, EdwardsC, Richards-

KortumR. "The impact of inaccurate internet health information in a secondary school learning environment." J Med Internet Res. 30 ${ }^{\text {th }}$ June 2008;10(2):e17 Available from URL: The impact of inaccurate Internet health information in a secondary school learning environment - PubMed (nih.gov)

52. JonesAM, OmerSB, BednarczykRA, H alseyNA, MoultonLH, SalmonDA. "Pa rents' source of vaccine information and impact on vaccine attitudes, beliefs, and nonmedical exemptions." Adv Prev Med. 2012;2012:932741-48. Available from URL: Parents' source of vaccine information and impact on vaccine attitudes, beliefs, and nonmedical exemptions - PubMed (nih.gov)

53. PerkinsRB, Fisher-

BorneM, BrewerNT. "Engaging

parents around vaccine confidence: proceedings from the national HPV vaccination roundtable meetings." 2019;15(7-8):1639-40. Available from URL: Full article: Engaging parents around vaccine confidence: proceedings from the National HPV Vaccination Roundtable meetings (tandfonline.com)

54. MohantyS, LeaderAE, GibeauE, Johns onC. "Using facebook to reach adolescents for human papillomavirus (HPV) vaccination." Vaccine. $25^{\text {th }}$ September 2018;36(40):5955-61. Available from URL: Using Facebook to reach adolescents for human papillomavirus (HPV) vaccination PubMed (nih.gov)

55. RobichaudP, HawkenS, BeardL, Morra D, TomlinsonG, WilsonK, KeelanJ. Va ccine-critical videos on YouTube and their impact on medical students' attitudes about seasonal influenza immunization: A pre- and post-study. Vaccine. $28^{\text {th }}$ May 2012;30(25):3763-
70. Available from URL: Vaccinecritical videos on YouTube and their impact on medical students' attitudes about seasonal influenza immunization: a pre and post study PubMed (nih.gov)

56. MasseyPM, BudenzA, LeaderA, Fisher K, KlassenAC, Yom-TovE. "What drives health professionals to tweet about \#HPVvaccine? Identifying strategies for effective communication." Prev Chronic Dis. 22 ${ }^{\text {nd }} \quad$ February $2018 ; 15: E 26$. Available from URL: What Drives Health Professionals to Tweet About \#HPVvaccine? Identifying Strategies for Effective Communication PubMed (nih.gov)

57. OehlerRL. "On measles, vaccination, social media activism and how to win back our role as our patients' best advocates. Clinical Infectious Diseases: An Official Publication of the Infectious Diseases Society of America." $15^{\text {th }}$ July 2019. Available from URL:On Measles, Vaccination, Social Media Activism, and How to Win Back Our Role as Our Patients' Best Advocates | Clinical Infectious Diseases | Oxford Academic (oup.com)

58. ShoupJA, WagnerNM, KrausCR, Nar waneyKJ, GoddardKS, GlanzJM. "Dev elopment of an interactive social media tool for parents with concerns about vaccines." Health Educ Behav. 19 November 2015;42(3):302-12. Available from URL: Development of an Interactive Social Media Tool for Parents With Concerns About Vaccines - Jo Ann Shoup, Nicole M. Wagner, Courtney R. Kraus, Komal J. Narwaney, Kristin S. Goddard, Jason M. Glanz, 2015 (sagepub.com)

59. DonovanJ. "Social-media companies must flatten the curve of misinformation." Nature. $14^{\text {th }}$ April 2020. Available from URL:Socialmedia companies must flatten the curve of misinformation (nature.com) 
60. Kasulis K. "Patient 31" and South Korea's sudden spike in coronavirus cases". Aljazeera. $3^{\text {rd }}$ March 2020. Available from: URL: https://www.aljazeera.com/news/2020/ 03/31-south-korea-sudden-spikecoronavirus-cases200303065953841.html?xif=.

61. K. Goyal, P. Chauhan, K. Chhikara, P. Gupta, M.P. Singh. "Fear of COVID 2019: first suicidal case in India!".Asian J. Psychiatry, 49 (2020), Article e101989, Available from: URL:

https://www.sciencedirect.com/science /article/pii/S1876201820300976?via\% 3Dihub

62. S. Sahoo, S. Bharadwaj, S. Parveen, A. P. Singh, C. Tandup, A. Mehra, S. Gro ver. "Psychometric validation of the Bangla fear of COVID-19 scale: confirmatory factor analysis and Rasch analysis". Int. J. Mental Health Addict. (2020), Available from: URL: https://link.springer.com/article/10.100 7\%2Fs11469-020-00289-x\#citeas

63. Kaur H. "Can the Indian legal framework deal with the COVID-19 pandemic? A review of the Epidemic Diseases Act". $27^{\text {th }}$ March 2020. Available from: URL: https://www.barandbench.com/column s/can-the-indian-legal-framework-dealwith-the-covid-19-pandemic-a-reviewof-the-epidemics-diseases-act

64. Joe W. "Coronavirus: Indian man "died by suicide" after becoming convinced he was infected".Published on $12^{\text {th }} \mathrm{Feb} 2020$. Available from: URL:

https://www.telegraph.co.uk/globalhealth/science-and-

disease/coronavirus-indian-man-diedsuicide-becoming-convinced-infected/

65. Busari S, Adebayo B. "Nigeria records chloroquine poisoning after Trump endorses it for coronavirus treatment". CNN. 23 ${ }^{\text {rd }}$ March 2020. Available from: URL: https://edition.cnn.com/2020/03/23/afri ca/chloroquine-trump-nigeriaintl/index.html

66. Spencer SH. "False Claims of Nationwide Lockdown for COVID19". $16^{\text {th }}$ March 2020. Available from: URL:

https://www.factcheck.org/2020/03/fal se-claims-of-nationwide-lockdownfor-covid-19/.

67. Pallavi pundir. "India's CoronavirusLinked Suicides Prove Misinformation Can Be Fatal". 01 July 2020. Available from:

URL:

https://www.vice.com/en_in/article/wx qxwn/india-coronavirus-suicide-fakenews?utm_source=viceinstain

68. Srivastava, K.C., D. Shrivastava, K.G. Chhabra, W. Naqvi, and A. Sahu. "Facade of Media and Social Media during Covid-19: A Review." International Journal of Research in Pharmaceutical Sciences 11, no. Special Issue 1 (2020): 142-49. https://doi.org/10.26452/ijrps.v11iSPL 1.2288 .

69. Bakshi, S., V. Toshniwal, A. Agrawal, S. Acharya, and S. Shukla. "Awareness and Psychosocial Effects of Covid-19 Pandemic on Health Care Professionals and Medical Students across the State of Maharashtra." International Journal of Current Research and Review 12, no. 22 Special Issue (2020): S-122-S-125. https://doi.org/10.31782/IJCRR.2020.S P74.

70. Kaple, M.N., C. Mahakalkar, M. Philip, and S. Kshirsagar. "COVID 19 Pandemic: Social Aspects and Safe Behaviours." Journal of Critical Reviews 7, no. 8 (2020): 1066-69. https://doi.org/10.31838/jcr.07.08.222.

71. Toshida, T., and C. Jagruti. "COVID19 - Rumours and Facts in Media." International Journal of Research in Pharmaceutical Sciences 11, no. Special Issue 1 (2020): 171-74. https://doi.org/10.26452/ijrps.v11iSPL 1.2344 . 
72. Gaidhane, A., A. Sinha, M. Khatib, P. Simkhada, P. Behere, D. Saxena, B. Unnikrishnan, M. Khatib, M. Ahmed, and Q.S. Zahiruddin. "A Systematic Review on Effect of Electronic Media on Diet, Exercise, and Sexual Activity among Adolescents." Indian Journal of Community Medicine 43, no. 5 (2018): S56-65. https://doi.org/10.4103/ijcm.IJCM_143 -18 . 